\title{
Women and HIV: Understanding and addressing stigma-Evidence from the Population Council
}

Population Council

Follow this and additional works at: https://knowledgecommons.popcouncil.org/departments_sbsr-hiv

Part of the Gender and Sexuality Commons, International Public Health Commons, Virus Diseases Commons, and the Women's Health Commons

How does access to this work benefit you? Let us know!

\section{Recommended Citation}

Population Council. 2019. "Women and HIV: Understanding and addressing stigma-Evidence from the Population Council," fact sheet. Washington, DC: Population Council. 


\section{WOMEN AND HIV: UNDERSTANDING AND ADDRESSING STIGMA EVIDENCE FROM THE POPULATION COUNCIL}

Globally, women bear a disproportionate burden of HIV and AIDS. Women account for more than half of the population living with HIV worldwide and young women (ages 15-24) are twice as likely to acquire HIV compared to young men. A variety of social, structural, behavioral, and biological factors shape women and girls' risk and vulnerability to HIV. One of the most important factors is stigma. While significant strides have been made in HIV prevention, care, and treatment programming, HIV-related stigma remains a significant barrier to women's equitable access to quality health services and care.

Over the last 20 years, the Population Council has carried out extensive work examining the intersection of stigma and gender and its impact on HIV-related outcomes. This brief summarizes key Population Council findings from a range of studies which elucidate the experiences of stigma among women and highlights avenues for addressing stigma to mitigate women's risk and burden of HIV.

\section{STIGMA IN THE LIVES OF WOMEN}

\section{Underlying norms on sexuality and morality affect women's access to HIV and health services.}

Evidence from multiple Council studies show that women, particularly sexually active unmarried young women, often encounter instances of stigma and discrimination when seeking treatment for sexually transmitted infections (STIs) or HIV testing. Because of local understandings of morality, gender, and sexuality, sexually active unmarried young women may face blame and judgement directly from health care providers, reducing their satisfaction with health services and discouraging them from pursuing HIV testing or treatment. Young women also face similar judgements from community members if they are seen using HIV-related health services.

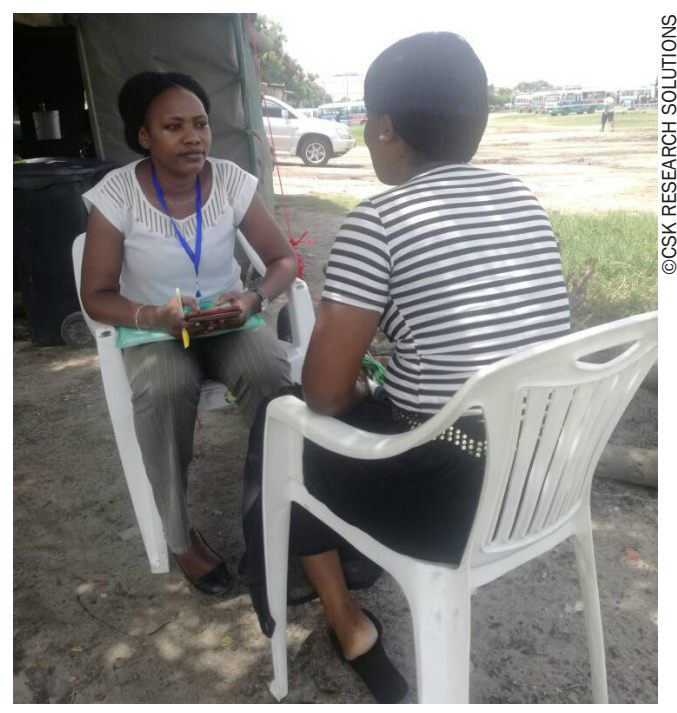

As part of Project SOAR, the Population Council tested a community-based distribution of antiretrovirals model for female sex workers in Tanzania. 
For instance, a young woman from South Africa noted:

\begin{abstract}
4 Nurses sometimes do not want to listen to young people. They judge us and ask why you are sleeping with men when you are not married. They also discuss us with people they know in the community. For example, if you went to the clinic because you had an STI, everyone in the community will know that and sometimes even your family.

-Young woman, South Africa
\end{abstract}

\section{Health providers' views on gender and sexuality can also hinder young women's access to HIV technologies.}

Council's research in Tanzania shows that health care providers in general support the availability of new biomedical technologies (i.e., oral pre-exposure prophylaxis or PrEP) as an HIV prevention strategy for young women. However, providers with negative attitudes toward adolescent sexuality and providers who thought PrEP use would lead to behavioral disinhibition (more risky sexual behavior) were less willing to prescribe PrEP to young women.

I have doubts on the availability of
PrEP. People may become care-
less and get involved in sexual activities
knowing that there is a preventive
measure for HIV. People had been living
with fear of getting HIV infection and
they were using condoms. Also, many
had refrained from sex; but now they will
revert to bad habits.

-Male clinical officer, Tanzania

\section{Anticipated stigma inhibits women living with HIV (WLHIV) from seeking healthcare and disclosure of status.}

Findings from Council research show that WLHIV fear encountering stigmatizing attitudes from healthcare providers especially when seeking sexual and reproductive health (SRH) and family planning (FP) services. Many WLHIV avoid seeking SRH services and do not disclose their status to providers, which can lead to inadequate treatment. A study in Kampala, Uganda among people living with HIV found that half of the respondents had hidden their HIV status from others, and more than half had delayed testing due to fears about how others would react if they tested positive.

\section{Pregnant WLHIV encounter stigma during pregnancy and childbirth.}

Council evidence also shows that HIV-positive pregnant women encountered stigmatizing attitudes from health providers when accessing prevention of mother-to-child transmission (PMTCT) services and while trying to find practitioners to deliver their child. Not only did women report difficulties finding practitioners who were aware of the needs of HIV-positive women and willing to accept them as patients, but many were scrutinized, judged, and scolded by providers for being pregnant while HIV positive. Women risk being the object of social and moral scrutiny for risking passing on the virus to their future child.
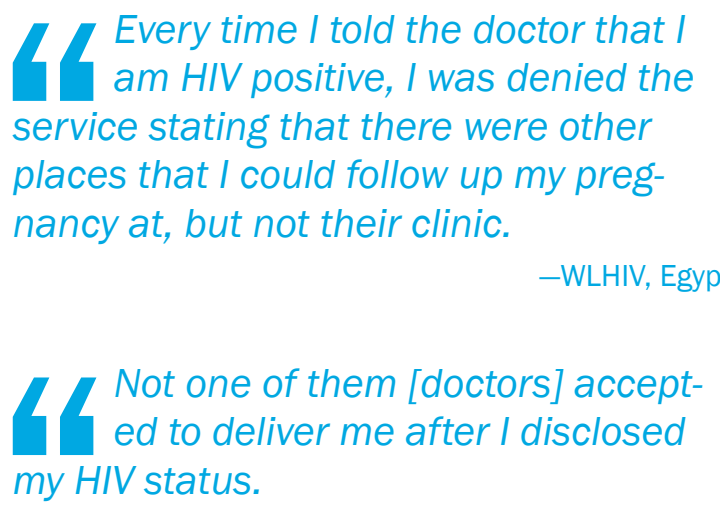

-WLHIV, Egypt

\section{WLHIV experience stigma from other members in their communities when breastfeeding.}

After giving birth, stigma can also impact breastfeeding practices among WLHIV. According to results from Kenya, respondents lacked comprehensive information on breastfeeding and HIV, and some only breastfed for a few weeks because of fear of transmitting the virus to their baby. While others who did not breastfeed hid the fact that they were not breastfeeding because people in their community could take it as a sign of being HIV positive, which would ignite gossip and judgement. 
44 I hear many gossiping and saying "so and so had the virus and is giving birth. Why is she giving birth?" They even follow her to the house to see if she is breastfeeding. If they find she is not breastfeeding they go say she has the virus. [...] saying she is giving the virus to the children.

-WLHIV, Kenya

\section{Women engaged in sex work fear recognition and disclosure in their communities.}

Council findings from Zambia show that female sex workers (FSWs) are wary of being recognized by their clients when seeking services in their neighborhoods. Due to the criminalization and stigmatization of their activities, anticipated stigma deters FSWs from accessing health services. Anticipated stigma also keeps FSWs from disclosing their sexual practices or STI symptoms to health care providers.

\section{Broader SRH needs of WLHIV, including women engaged in sex work, are rarely recognized by health care providers.}

Given the vertical structure of health services, SRH and FP providers are not necessarily informed or sensitive to the needs of HIV-positive women. While there has been a significant amount of attention to the integration of SRH and HIV services, particularly regarding HIV testing and antenatal care, there has been a comparative lack of attention on the SRH needs of WLHIV. This may lead to SRH and FP providers perpetuating stigmatizing views and actions toward HIV-positive women, such as dismissive, disrespectful, and moralizing attitudes, as well as rejection after HIV status disclosure.

Council findings from Tanzania show that HIV-positive FSWs have both a need for contraception as well as a desire to have children in the future. However, FSWs are not always asked about their fertility desires or counseled regarding contraception and safer conception options. A survey with over 600 FSWs showed that only 33 percent were aware that effective HIV treatment by the HIV-positive partner could virtually eliminate the risk of HIV transmission and allow for safe conception.

\section{STRATEGIES TO ADDRESS HIV- RELATED STIGMA AMONG WOMEN}

Building on the Population Council's research, we highlight below strategies to address stigma and/or facilitate women's access to services free of judgement and stigmatizing attitudes:

- Train and sensitize healthcare providers. Women deserve access to respectful healthcare services. It is therefore necessary to ensure that providers are trained on how to provide holistic and judgement-free HIV and reproductive health services and counseling to all women-particularly young women, HIV-positive women, and women engaged in sex work. Evaluation of the Council's training programs in Bangladesh showed important reductions in providers' stigmatizing beliefs regarding FSWs and sexually active young women. Both young people as well as FSWs reported experiencing a decrease in stigmatizing attitudes and discriminatory behaviors among providers, as well as an improvement in their overall satisfaction with services. Furthermore, provider agreement that sexually active young people more broadly engage in "immoral behavior" decreased.

- Bring HIV services to the community. Communitybased delivery of antiretroviral therapy (ART) offer an alternative to facility-based HIV services for populations who avoid healthcare settings due to stigma, such as FSWs. A Council-led study in Tanzania testing the effects of community-based distribution of ART has shown success in providing HIV treatment in a respectful and non-judgmental way to FSWs. ART initiation and retention, and satisfaction with services was higher among FSWs receiving community ART than the standard of care.

- Tap the potential of virtual counseling to avoid and reduce stigma. Given the stigmatizing attitudes that pregnant WLHIV have encountered from providers, a Council-led intervention in Kenya offered an innovative way of providing PMTCT counseling to HIV-positive pregnant women through mobile phones. The intervention was successful in raising antenatal and postnatal care attendance rates among participants, as well as reducing perceived stigma from providers. 
- Create safe spaces for young women. The Council has successfully implemented and assessed multi-component empowerment programs for adolescent girls and young women in Malawi, Zambia, and Kenya that aim to address young women's HIV risk, as well as contextual factors which perpetuate stereotypical and stigmatizing views of women's sexuality and reproductive rights. A core component of these interventions are safe spaces in the community, where young women can gather on a periodic basis and with the aid of a mentor discuss health and life skills information and access health services. These efforts are showing promising shifts in women's self-efficacy toward accessing HIV care, lower anticipated stigma, enhanced risk perception, and increased awareness of prevention and care options.

\section{- Expand HIV prevention options for women. The} development of PrEP has been a significant tool in giving women autonomy in relation to protecting themselves from possible HIV transmission. Along these lines, the Council is continuously working on developing new user-controlled prevention methods, such as multipurpose prevention technologies, which allow women to prevent HIV, STIs, as well as unintended pregnancy. This gives women greater choice and power in relation to their HIV prevention strategies.

Evidence generated by the Population Council has shown that HIV-related stigma remains a crucial obstacle in women's access to HIV services, and that addressing it is a critical step toward improving HIV prevention and treatment outcomes. Eradicating HIVrelated stigma in the lives of women affected by and living with HIV, requires transforming views on women's sexuality and sexual practices, recognizing and meeting the broader SRH needs of WLHIV, and shifting the way we reach the most marginalized women. Moving forward, the Population Council will continue generating evidence on women's experience of stigma, as well as developing and testing interventions to tackle these issues, as a central part of its HIV and AIDS response.

\section{REFERENCES}

Ahonsi, B. et al. 2014. "HIV/AIDS vulnerabilities, discrimination, and service accessibility among Africa's youth: insights from a multi-country study." Abuja: Population Council. https://www.popcouncil.org/uploads/pdfs/2014HIV_SixCountryYouthFinalReport. pdf

Austrian, K. et al. 2018. “Adolescent Girls Empowerment Program (AGEP): Health," Brief. Lusaka: Population Council. https://www. popcouncil.org/uploads/pdfs/2018PGY_AGEP-HealthBrief.pdf

Colombini, M. et al. 2014. "Experiences of stigma among women living with HIV attending sexual and reproductive health services in Kenya: a qualitative study," BMC Health Services Research 14(1): 412. doi: 10.1186/1472-6963-14-412

Geibel, S. et al. 2017. "Stigma reduction training improves healthcare provider attitudes toward, and experiences of, young marginalized people in Bangladesh," Journal of Adolescent Health 60(2): S35-S44. doi: 10.1016/j.jadohealth.2016.09.026

NAFOPHANU and Project SOAR. 2019. "HIV stigma in Kampala District: results from testing the People Living with HIV Stigma Index 2.0," Project SOAR Results Brief. Kampala: Population Council.

Oraby, D. and N. Abdel-Tawab. 2014. "Sexual and reproductive health of women living with HIV in Egypt: Unmet needs and unfulfilled dreams." Cairo: Population Council. https://www.popcouncil. org/uploads/pdfs/2014RH_SRH-Egypt.pdf

Pilgrim, N. et al. 2018. "Provider perspectives on PrEP for adolescent girls and young women in Tanzania: The role of provider biases and quality of care," PLoS One 13(4): e0196280. doi: 10.1371/ journal.pone.0196280

Population Council. 2016. "The Population Council: pioneering new tools to prevent HIV, STIs, and unintended pregnancy" Factsheet. New York: Population Council. https://www.popcouncil.org/uploads/pdfs/2016HIV_MPTfactsheet.pdf

Project SOAR. 2018. "Early results demonstrate the importance of early treatment of HIV and the feasibility and acceptability of community-based antiretroviral treatment delivery for female sex workers in Tanzania," Project SOAR Results Brief. Washington, DC: Population Council. http://www.projsoar.org/wp-content/uploads/2018/05/Tz_FSW_BsIn_ResBrief.pdf

Project SOAR. 2018. "The People Living with HIV Stigma Index 2.0: results from pilot testing in three countries," Project SOAR Results Brief. Washington, DC: Population Council. http://www.projsoar.org/ resources/stigma-index-pilot-results-brief/

Sarna, A. 2019. "Cell phone counseling improves retention of mothers with HIV infection in care and infant HIV testing in Kisumu, Kenya: a randomized controlled study," Global Health: Science and Practice 7(2): 171-188; https://doi.org/10.9745/ GHSP-D-18-00241
POPULATION COUNCIL

Ideas. Evidence. Impact.
The Population Council confronts critical health and development issues-from stopping the spread of HIV to improving reproductive health and ensuring that young people lead full and productive lives. Through biomedical, social science and public health research in about 50 countries, the Council works with our partners to deliver solutions that lead to more effective policies, programs, and technologies to improve lives worldwide. Established in 1952 and headquartered in New York, the Council is a nongovernmental, nonprofit organization with an international board of trustees.

Suggested citation: Population Council. 2019. "Women and HIV: understanding and addressing stigma-evidence from the Population Council," Factsheet. Washington, DC: Population Council. 